\title{
Christopher Columbus, King Canute and SARS: the name does matter
}

The recent outbreak of SARS is a hot topic. Although it does seem to be settling down now I thought I would raise it with Charles.

'I am relieved that the SARS epidemic appears to be settling down,' I said to Charles.

'Will it be back, Coe?' he replied.

'Quite likely; what should be done if it does?'

'Certainly we shouldn't panic Coe, and maybe we should let it spread!' Not for the first time I was taken aback; seeing my surprise he continued, 'Can it be stopped every time?'

'Probably not in the long run,' I admitted.

'Then why should we try the impossible?'

'I can think of at least two reasons; to allow time for cure and the development of a vaccine' was my reply.

'Actually I thought them two parts to the same answer, but is the first realistic?'

'No,' I confessed.

'And how long will the second take?'

'At least two years.'

'That sets the time scale,' he said.

'But in the meantime we must make some attempt to contain the disease,' I protested. 'If not, the health services will be overwhelmed, particularly as many of the staff are likely to become patients. Furthermore there would be the health consequences of economic disruption.' I reminded him of the high morbidity and mortality in rural communities resulting from the recent foot and mouth disease.

'Disruption was indeed my other reason,' he replied. 'I agree the implications of inaction are potentially disastrous for health services but the more general issue of economic disruption is not so simple. The question is - what will cause more disruption, allowing the virus to spread rapidly or trying to contain it?'
After a moment's thought I realised that that was a difficult question to answer. 'To allow spread would affected,' I replied. 'But containment would result in disruption to the majority lasting years.'

'An impossible equation' he said.

'Yes,' I replied adding, 'To tell you the truth I have got a further niggling doubt in my mind.'

'What's that?'

'Any prolonged disruption of air travel almost certainly will be followed by a rapid rebound,' I replied. 'We know what happens when disparate people are suddenly brought together; think of the devastation caused by the infectious agents inadvertently brought to Hispanolia by Columbus's men. I wonder if air travel is just as important in maintaining herd immunity from endemic mild strains of influenza as it is in spreading the dangerous mutant. Hong Kong flu might have had its mortality, but Spanish flu was far more deadly.'

'Mass transport may act as an angel by immunising the population as well as the devil in spreading a deadly form of the virus.'

'That's the idea,' I said.

'Is influenza more dangerous?'

'Probably,' I replied, 'certainly when associated with coccal infection. Mortality rates are above $66 \%$ despite antibiotics and the mortality from SARS is probably $13 \%$ at most.'

'How can you say that - do you know the denominator?' he said.

'I suppose we don't until epidemiological studies show the sub-clinical infection rate.'

'And that will take about two years as well?' he replied.

'Yes,' I said, 'it will.' 
'I also have reservations about the name SARS', he said. 'How did it arise? Wasn't it the clinical description of a few patients before the nature of the problem was established?'

'That is true,' I said.

'Isn't that a good description of the clinical picture of any overwhelming pneumonia? So the virus is named after its most severe effect which occurs in a proportion of patients that at present must necessarily be over-estimated?'

'Yes.'

'Wouldn't it be far better to call it by its family name rather than implying that it always produces a severe illness?'

'Perhaps, but so what?' I replied, not really convinced.

'My point is that the name really does matter. As you know, unlike King Canute, the coastal authorities on the East of England have decided that managed retreat is the right approach. Think of the public and press reaction if the health authorities have reluctantly to come to the same conclusion and "a severe illness is allowed to let rip throughout the country"!'

I knew what he was thinking - 'another example of modern society's inability to cope with rapid communication demanding absolute knowledge and absolute safety' - whilst I thought the influenza argument might apply to SARS itself. Might it be better to allow SARS to spread with the minimum number of generations to establish herd immunity before an even more virulent strain occurs? 